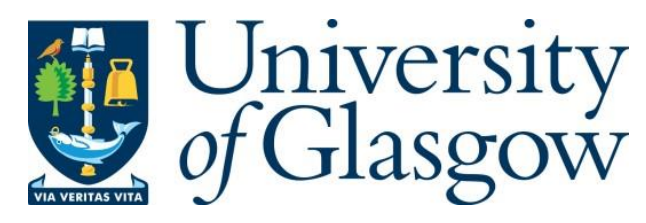

Busby, N. and Weldon-Johns, M. (2019) Fathers as carers in UK law and policy: dominant ideologies and lived experience. Journal of Social Welfare and Family Law, 41(3), pp. 280-301. (doi:10.1080/09649069.2019.1627085)

There may be differences between this version and the published version. You are advised to consult the publisher's version if you wish to cite from it.

http://eprints.gla.ac.uk/207669/

Deposited on: 23 January 2020

Enlighten - Research publications by members of the University of Glasgow http://eprints.gla.ac.uk 


\section{Fathers as Carers in UK Law and Policy: Dominant Ideologies and Lived Experience}

Nicole Busby and Michelle Weldon-Johns*

Title Page Footnote:

* Prof Nicole Busby, University of Strathclyde, Lord Hope Building, 141 St James Road, Glasgow, G4 0LT, 01415483965 , nicole.busby@strath.ac.uk

Dr Michelle Weldon-Johns, Abertay University, Old College, Bell Street, Dundee, DD1 1HG, 01382 308149, m.weldon-johns@abertay.ac.uk (corresponding author) 
This article explores how working fathers are conceptualised within the UK's work-family law and policy framework and whether a dominant ideology of fatherhood can be discerned. The socio-legal literature on men and masculinities is considered alongside established feminist theory on families, paid work and unpaid care to provide a backdrop to the analysis of current policy provision in this area. Three 'ideal' type ideologies of fatherhood are identified ('absent', 'involved' and 'active') which are used to critically examine the current legal framework. Despite claims to the contrary, the current framework supports and reaffirms the gendering of care so that the intransigence on the part of men and women to rebalance related responsibilities is unsurprising. The authors argue for a more care-centric approach to work-family policy in place of gender-specific normative modelling. A legal framework which enabled and encouraged all care providers to participate regardless of gender and biological relationship would not only improve the workplace experiences of women, but also enable men to develop and fulfil their care-giving aspirations and potential.

Keywords: Fatherhood, work-life balance, parenting

\section{Introduction}

McGlynn's (2000) analysis of the dominant ideology of motherhood underpinning EU law underscored the highly gendered nature of legislative and judicial approaches to the work-family conflict. This has had significant implications for working mothers, who continue to bear the principle responsibility for childcare. It also has related consequences for working fathers, by reinforcing a particular ideology of fatherhood, with limited responsibility for care. This is notably at odds with the policy dynamic on 'new fatherhood' which carries expectations of greater paternal responsibility for care. The language of 'new' and 'involved' fatherhood, and the promotion of shared responsibility for care, has underpinned recent developments in the UK.

In this article we consider the development and effectiveness of UK law and policy intended to enable and encourage men to reconcile paid work with family life. By assessing the relevant framework against the backdrop of prevailing assumptions about what it means to be a father, we seek to identify whether the particular conceptualisation adopted by policy-makers in this respect can be said to comprise an overarching or dominant ideology of fatherhood. In so doing, we question whether the use of such an ideology is possible or desirable in this context and conclude that this approach is likely to be self-defeating with better results achievable through 
flexibility and choice enabling shared care arrangements wherever possible based on intimate relationships and regardless of the gender and parental status of the providers. This analysis is timely as recent CJEU jurisprudence and the proposed Work-Life Balance Directive suggest that a new ideology of fatherhood is emerging at the EU level (Caracciolo di Torella, 2014 and Fredman, 2014). However, more recent decisions in the UK around shared parenting indicate an entrenchment of traditional gender roles. With Brexit on the horizon, it is opportune to reflect on whether there is a dominant ideology of fatherhood in the UK's work-life balance regime and what the implications of Brexit might be for this in the future.

The paper is organised as follows. We begin by discussing the dominant ideology hypothesis with a particular focus on the notion of 'new fatherhood' which asserts that men have developed and/or are developing a stronger, more emotionally involved and hands on approach to parenting. This conceptualisation has influenced the state's approach in recent years so that an enhanced familial role for men underpins much of the law and policy framework (Gregory and Milner, 2011). In questioning the applicability of this ideal to lived experience, academic research has labelled it as conceptually 'problematic' (Collier, 1999; 2001;2010) largely due to its implicit acceptance of a hegemonic male identity (Hearn, 2004). The 'fragmentation of fatherhood' (Collier and Sheldon, 2008) has been catalysed over recent decades by sweeping social and economic changes which have been led by and impacted on social arrangements across many spheres including family formation, contemporary living arrangements and the gendered division of paid and unpaid labour. Despite the identification of a wide diversity in fathering practices, a continued attachment to the notion of 'new fatherhood' underpins the current policy shift which, at least ostensibly, offers support for gender-neutral parenting and care. In the second half of the paper the current package of work-family legislation in the UK is examined through the lens of three 'ideal-types' of fatherhood ideologies. These draw from and reflect the diversity of conceptions of fatherhood, focusing on characteristics which continue to dominate expectations of masculine identities and fathering roles. As this analysis reveals, the substantive provisions themselves and their broader law and policy context lack a cohesive objective and unifying ideology and, perhaps most pertinently, do not reflect any clear and realistic conception(s) of fatherhood. As the UK law and policy framework diverges from that of the EU as a result of Brexit, there is a danger that this will be reinforced. In conclusion, we argue that a true commitment to the de-gendering of care-giving would require a profound reworking of the whole law and policy framework relevant to the state's engagement with families and work, including unpaid care, and its many interrelated strands. This would encompass convergence of the currently separate spheres of family, social security and tax law as well as labour law and would require that care-giving be recognised and valued as an 
activity in its own right by work-family policy that places care at its centre rather than as a subsidiary concern to be fitted in around the demands of paid work. This is in contrast to the current framework which relies on a normative model of fatherhood which, in any case, is deployed differently in different policy contexts and which risks masking the diversity that characterises contemporary arrangements and parental aspirations.

\section{A 'Dominant Ideology' Hypothesis}

The reconciliation of paid work and unpaid care is an ongoing theme of feminist socio-legal scholarship which has focused attention on the family, socio-economic institutions and contemporary workplaces. Women's lived experiences as the primary providers of informal care have shaped the nature of their engagement with paid work and given rise to a resultant law and policy framework which is profoundly gendered. As well as acknowledging women's almost exclusive association with the 'private' realm of the family and men's

corresponding invisibility, such scholarship has highlighted men's dominance over the 'public' world of paid work and how, despite a permanent presence in the paid labour market, women's paid work continues to be characterised by low pay and status and increasing precariousness (Fudge and Owens, 2006). Such divergence in the experiences of women and men has been explained by an historically grounded narrative in which the socio-economic institutions that determine the nature and performance of paid work are portrayed as being steeped in essentialist assumptions about the delimiting effects of pregnancy and motherhood on women's labour force participation. Such an analysis shows how law and policy serve to reaffirm stereotypical ideals regarding the gendered order within which women are portrayed primarily as caretaker and homemaker and men as breadwinner. This dichotomisation is accommodated within the legal and policy framework to such an extent that even those provisions which are aimed at achieving gender equality can actually serve to replicate and further entrench such divisions (McGlynn, 2000, 29). As well as being predicated on established notions of motherhood, policy intervention in the area of work-life balance also relies on homogenised assumptions regarding what being a 'father' is, what it is becoming and what it should become. The state's intervention in this and other contexts has been referred to by Collier as '...no less than an attempt at socially engineering a 'new', 'improved' 'balance' between work and family life' (1999, 167). See also Smart (1997), which explores how the role and function of fathers in post-separation families was repositioned in order to make gender neutral policy that assumed, inter alia, non-resident fathers' ongoing commitment to provide child support. 
The reimagining of fatherhood through the construction of a legal and policy framework throws up certain conceptual problems. Fatherhood, at least in the context of caregiving, is a far more slippery concept than motherhood for which a clear and dominant ideology is at least discernible. However, as the pervasive conception of motherhood has shown, an over-reliance on stereotyping which fails to recognise the diversity in individual circumstances, practices and aspirations has made the whole exercise of normative modelling highly questionable. Essentialist notions of women's biological and psychological predisposition to care abound within the policy framework and have been particularly damaging to the attainment of gender equality (see Pateman 1988). Childcare continues to be so strongly associated with women that men's (theoretical) involvement is very much a background feature characterised by notions of the 'absent father'. This feeds into the figurative conception of fathers as marketised individuals whose primary concern is breadwinning, making the idea of a 'father as carer' more difficult to imagine as a legal subject, so that,

'Men's parenting is too often depicted as a social problem rather than a social strength. Fathers are often only visible in terms of their absence: working long hours, not living with their children or lacking legal rights as parents. An economic view of fathering continues to dominate policy discussions. As yet in debates about 'the family' there is little serious discussion about what policy makers and service providers can actually do to support men's parenting' (Lewis, 2000, 7).

In her consideration of the role of fathers in shared care arrangements, O'Brien echoes the language more commonly used in the converse context of mothers' workplace experiences by concluding that fathers 'are increasingly self-conscious about juggling conflicts between looking after children and having a job' (2005, 3). This is reflective of a growing normative expectation that fathers should be involved in caring for their children in a performance, rather than (financially) supportive, capacity (Dermott, 2008) as well as indications that men might actually be engaging in or seeking such enhanced involvement. According to research $82 \%$ of men have expressed such a desire (Park, Curtice, Thomson, Phillips and Johnson, 2007) and the Fatherhood Institute reports that a substantial number of fathers are now full- or part-time 'home dads': among fathers of underfives, $21 \%$ are solely responsible for childcare at some point during the working week and $43 \%$ of fathers of school-aged children provide care before/after school (Equality and Human Rights Commission, 2009).

In recent years the move towards dual earner households in which both partners engage in paid employment has been noted as a feature of all developed economies (Crompton, 1999). In some European countries women's employment rates now remain stable regardless of family formation and, even where women move from full- 
time into part-time employment once they have children their adherence to the labour market is in stark contrast to the low participation rates of previous generations (Abbott, Nativel and Wallace, 2013). In the British context, the increased participation of both parents in paid work outside the home certainly confirms that shared parenting and gender neutrality in care provision are desirable policy goals. In $201189 \%$ of fathers in couple households and $68 \%$ of mothers were in employment. A diverse set of working patterns among couples living together with children were identified with three types accounting for $82 \%$ of all such households: $31 \%$ of couples adhered to the classic one and a half earner (male FT and female PT) model; 29\% to the dual full-time earner (male FT and female FT) model; 22\% to the male full-time sole breadwinner model. Between 2001 and 2011 the proportion of households with two full time earners increased from $26 \%$ to $29 \%$ and the proportion of households with a father working full-time and a mother working part-time has decreased from $37 \%$ to $31 \%$. The proportion of male full-time sole breadwinner households has remained stable over the decade (Connolly, Aldrich, O’Brien, Speight and Poole, 2013).

Assuming that law has a normative value enabling it to lead as well as follow social change (Busby, 2011), what is required is supportive policy premised and underpinned by a clear ideological foundation aimed at addressing the inequality experienced by women/mothers in the labour market whilst, at the same time, helping to determine and support men's/fathers' place within the family and as worker-carers. This raises a number of challenges for policy-makers with a fundamental issue being how best to facilitate and encourage men's engagement with their children alongside their continuing participation in the paid labour market. The way in which the current legal framework attempts to do this will be considered in the second half of the article. First, we present an analysis of the wider policy and socio-economic context in which the provisions have developed.

\section{New Imaginings of Fatherhood and the Emergence of 'New Fatherhood'}

The state's continuing attempts to respond to the challenges presented by the changing composition of the postwar workforce as well as the emergence of an array of diverse family arrangements has led to a reconceptualisation of fatherhood in law and policy aimed at enabling parents to better balance work and family commitments (Dermott, 2001; Collier, 2001, particularly the discussion of the promotion of 'good fathering' at 527; Caracciolo Di Torella, 2007). Since its origins in the 1990s, such policy has ostensibly been underpinned by two key aims: to enable parents to combine work and care commitments and to promote gender equality, with the latter's achievement focused on encouraging fathers to undertake a greater role in family care. However, despite its association with equality objectives, the resulting policy framework has tended to reinforce 
a traditional view of fatherhood which does not afford fathers a clearly defined role in relation to childcare and related activities. While political rhetoric suggests that working fathers are/should be more actively involved in caring for their children, in practice the legislation has not always supported fathers' ability to be so nor has it easily facilitated the transfer of a greater share of unpaid care from mothers to fathers. This is particularly evident where work-family provisions interact with other wholly relevant policy strands such as social security and taxation. Academic work has focused on the disconnectedness between the policy ideal and lived experience, in particular, highlighting the key tensions that exist between the traditional role of fathers and notions of 'new fatherhood' and the rhetoric and reality of government policy in this area (Collier, 2001 and 2010; Collier and Sheldon, 2008; Smart and Neale, 1999).

'New fatherhood' emerged as a policy model in the UK in the late 1990s when the New Labour government promoted the inclusion and enhancement of the role of men/fathers within families (Caracciolo Di Torella, 2007). Despite two changes of government in 2010 and 2015 heralding a 'new approach' to equality, New Labour's policy trajectory in the current context has sustained up to the present day. Referring to the previous coalition government, Hepple (2011) observed that, despite a brutally deregulatory approach to some areas of labour law, there was continuity in 'New Labour's 'Third Way' of regulating for competitiveness and social inclusion, including in the area of work/life balance legislation with a continuation, not just of the previous administration's policy aims, but also of their underpinning ideology. However, although the policy rhetoric may remain the same, the political landscape against which recent developments have taken shape has changed considerably.

The programme of swingeing cuts to public services, public sector employment and social security benefits implemented by the coalition government and continued by the current Conservative administration is rationalised on the basis of the global economic crisis and national budget deficit but has a deeper ideological grounding in neo-liberal economic theory (Clarke and Newman, 2012). The impact has been keenly felt by women in their role as the primary providers of unpaid care which has been marginalised by policy attempts to rebalance the relationship between paid work and welfare (Busby, 2014). Furthermore, the public sector equality duty (PSED) (Equality Act 2010 c.15 (EqA), s.149), by which public authorities are required to assess public policy's equality impact, has failed to deliver on its promise of a proactive approach to the elimination of inequalities (Equality and Human Rights Commission, 2017). Although it survived the hollowing out of the EqA, the PSED is a pared-down version of its predecessor, the gender equality duty (GED), which was hailed 
by the Equal Opportunities Commission as the biggest advance in women's equality since the 1970s (Equal Opportunities Commission, 2006) and which would have offered women better protection against the harshest effects of the austerity programme.

The cuts agenda has contributed to an entrenchment of gendered roles with a regression in the achievement of gender equality (MacLeavy, 2011; Conley, 2012; Busby, 2014). Although this has not signalled a reduction in mothers seeking and/or remaining in paid work - a major plank of the employment/welfare strategy has been a push towards higher labour market participation rates for mothers - the shift from public to private sector employment and reduction in public services has increased the precarious nature of much of that work. The impact on mothers' paid work/unpaid care arrangements is likely to have had an associated effect on fathers' enhanced engagement in family care. This is likely to be exacerbated further by Brexit, particularly since EU membership previously prevented deregulation in some of these areas (Busby, 2018).

Despite such a changing political landscape, 'new fatherhood' has provided a consistent model for policymakers concerned with the reorientation of work/family balance and corresponding gender roles. Under this conceptualisation a father's role within the family has been reconstructed as more hands-on and emotionally engaged so that men are portrayed as wanting to spend time caring for their children alongside their paid work. However, despite indications that men's contributions to unpaid domestic work and childcare have increased alongside women's engagement with paid employment, the rate at which this has happened is nowhere near equivalent (Gershuny, 2000; Dex, Hawkes, Joshi and Ward, 2005; Crompton and Lyonette, 2008; Working Families, 2011). The reasons for men's lack of enthusiastic engagement with childcare is undoubtedly attributable to established notions of what it is to be a 'good dad' which find expression both in prevailing social norms that are, in turn, led and supported by the law and policy framework making it difficult to ascertain whether and/or how policy development can influence behaviour in this context. Policy-makers' attraction to a particular reimagining of fatherhood which utilises law's normative capacity to reorient gender roles is apparent but how achievable is this, particularly given government's commitment to a neo-liberal economic model which entrenches the traditional gendered division of paid work/unpaid care?

\section{Towards a Normative Model of Fatherhood?}

Law and policy's effectiveness as a means of influencing and encouraging a more 'hands on' and emotionally involved style of fathering relies on the assumption that there is a pre-existing desire among men to engage in 
such care. Whether this is in fact the case has been the subject of academic focus for some time. Collier has asserted that it is problematic to assume that all (or even the majority of) men want to acquire a greater role in the provision of family care (Collier, 1999). Miller has shown that, even where new fathers aspire to be more involved in caring for their child compared with earlier generations, 'a return to paid work reveals the temporary nature of any intentions - or possibilities - to significantly disrupt normative gender behaviours' (2011a, 1107 and Miller 2011b) so that fathers (and mothers) quickly 'fall back into gender'. Dermott's (2001 and 2005) work has shown that there is no 'one size fits all' model capable of reflecting men's desires and behaviour in this respect. By asking fathers about their experiences and views relating to taking (unpaid) parental and paternity leave, Dermott identified three different conceptions of fathering with each denoting varying degrees of support for the idea that fathers should take such leave. Interestingly, 'the language of 'involvement' and 'participatory fathering' was not exclusive to any one group but present among all fathers' (2001, 160) demonstrating that affirmative verbal expression is not necessarily translated into behaviours.

According to Collier the changing status of fatherhood can clash with traditional conceptions of masculinity leading to conflict between the 'breadwinning' notion of fatherhood and policy ideals associated with 'new fatherhood' $(1995,526)$. Central to this mismatch between policy aspiration and lived experience are gendered identities for which the prevailing norms relating to behaviour and aspiration are shifting. Writing in 2001, Collier noted that 'fatherhood' does not form part of the hegemonic male identity which is more strongly related to other activities such as paid work. However, more recent work stresses the 'complexity, change, inconsistency and contradiction' (Collier and Sheldon, 2008, 236) inherent in attempts to construct an idea of fatherhood as a unitary concept and focuses on developing understandings of fatherhood as 'open-ended, fluid and fragmented' (Collier and Sheldon, 2008, 234). Such shape-shifting is also a central theme of Dermott's work in which she argues convincingly for a reconceptualisation of the way in which we think about contemporary fatherhood and calls for the adoption of an organising concept which 'allows for the examination of personal relationships both in terms of orientations and tasks: that is, what is being sought from and offered in a father-child relationship as an ideal and in terms of practical caring' $(2008,1)$.

Under this contemporary formulation, the concept of 'male identity' masks more diversity than it seeks to unite: it remains the case that 'paid employment and the 'breadwinner ethic' are of central significance in the formation of a distinctive masculine identity for many men' (Collier and Sheldon, 2008, 130), yet 'there is substantial evidence that the social experience of fatherhood (and of being fathered) has shifted, and is shifting, in both 
quantitative and qualitative respects' (Collier and Sheldon, 2008, 128). The world of paid work is also changing with women's increased labour market participation characterised as the 'feminisation of the workplace'. State goals to encourage and facilitate women's labour market participation have led to a focus on law and policy intended to facilitate 'work/family balance' by way of so called 'family friendly' provisions with the deployment of language aimed at denoting a cosy, care-centric approach masking a range of unresolved tensions. The notion that a growing female labour force has inspired a revolution in workplaces so that they have become more 'feminised' and, presumably, more attuned to what is seen as a traditional female preoccupation with care obligations is highly questionable, not least because of its reliance on gender stereotyping. While it is true that there has been a substantial increase in the range of care-related rights available to women and, in more limited circumstances, men, this has not necessarily been accompanied by a corresponding shift in workplace culture. Many women continue to be employed in those sectors traditionally associated with 'women's work', typically in the expanded service sector, in a narrow range of jobs at the low paid, low status and often precarious end of the labour market (Fudge and Owens, 2006; Busby, 2011, Chapter 3). Furthermore, women are more likely than men to work part-time or under other 'flexible' work arrangements to enable them to continue to provide primary care for children and others alongside paid employment, with the gendered pay gap even more prominent when women's part-time pay rates are compared with men's full-time rates (Fudge and Owens, 2006; Busby, 2011, Chapter 3). As discussed above, policy attempts to promote a better work-family balance for women and men have heralded only a slight increase in the numbers of men acquiring sole or shared responsibility for childcare (Working Families, 2011) with the austerity agenda likely to lead to an increase in the precariousness which characterises many women's labour market experiences.

This challenges another pervasive assumption underpinning policy interventions, i.e. that women's participation in paid work has had an impact on the division of labour within households. In this context it is evident that there is resistance amongst men to change in the ways in which policy-makers would perhaps like them to. One reason for this is that, despite the headline statements to the contrary, the existing law and policy framework supports and perpetuates the status quo through the consistent application of a (negative) model reaffirmed by the courts which exemplifies a care-less conception of male identity (this point has been articulated in the family law context by Herring, 2014). The overriding assumption is that, in the heterosexual two-parent family, the father's engagement in paid work implies his corresponding absence from the home or, at best, his secondary role to that of the mother's in unpaid caregiving and associated family-centred responsibilities with any associated rights being derivative or reliant on those granted to the mother. This point, which will be expanded 
upon in the second part of this paper, echoes McGlynn's thesis that the dominant conception of motherhood 'is closely related to normative notions of the 'family': it legitimises the existing sexual division of labour and particular designated roles for fathers (breadwinner, protector and authority figure)' (2000, 34). Furthermore, women's increased labour market participation has undermined the traditional 'breadwinner' notion of fatherhood further, making it difficult for many men to know what their identity as fathers should look like and, thus, what is expected of them (Collier, 2010, 129 (and further at 138) in which he asserts that the drawing of a formal legal framework around equality which stresses gender neutrality in parenting as the ideal has problematised fatherhood.).

To summarise, current policy provision dictates that to in order to be 'good fathers' men should be encouraged to acquire greater caring responsibilities. Based on a set of assumptions which treat 'masculinity' and 'fatherhood' as homogenous concepts, this approach represents a considerable shift in expectations and produces something of a contradiction when placed alongside the more traditional notions of masculinity reinforced elsewhere in the policy landscape. Against this unsettled backdrop, we now consider the current legal framework to determine the extent to which it recognises the diversity that characterises fatherhood and is, thus, capable of enabling all fathers to adopt caring roles.

\section{Framing Fathers' Parental Rights}

The second part of the paper examines the current work-family framework through the lens of three 'ideal-type' ideologies' of fatherhood drawing on the literature discussed in the first section, particularly in relation to diversity and fragmentation (Collier, 2010 and Collier and Sheldon, 2008). This spectrum of ideologies ranges from traditional conceptions of fatherhood and responsibilities for care, to more active engagement and shared responsibility for care. At one end is the 'absent' fatherhood ideology, which represents the traditional notion of paternal absence from the caring sphere, and which can be divided into two variants: absence due to primary breadwinning responsibilities and absence due to non-resident parenting status. The mid-point is the 'involved' fatherhood ideology, which represents the rhetoric of 'new fatherhood' by attempting to involve fathers in care (Smart and Neale, 1999). However, this is also characterised by a failure to challenge traditional relationships of care, instead maintaining the status quo in practice. At the other end of the spectrum is the 'active' fatherhood ideology, which embodies the ideals and expectations of involved fatherhood and shared responsibilities for care, both in policy and in practice. This framework enables a critical assessment of whether the legislation itself embodies a dominant ideology of fatherhood, and if so, whether this accords with the rhetoric on 
fatherhood employed in this context. The contribution of EU law to the UK framework and implications of Brexit on the future development of fathers' rights will also be considered. First a brief overview of fathers' work-family rights in the UK will be provided.

\section{Fathers' work-family rights}

Working fathers in the UK have access to work/family rights at three key stages of a child's life: the ante-natal period; the post-birth period; and the extended childhood period. During the ante-natal period all working fathers are entitled to a day-one right to unpaid leave to attend two ante-natal appointments of up to 6.5 hours each (Employment Rights Act 1996 c.18 (ERA), s.57ZE). In the immediate post-birth period, working fathers with 26 weeks continuous service by the end of the $15^{\text {th }}$ week before the expected due date are entitled to paternity leave (Paternity and Adoption Leave Regulations 2002/2788 (PALR), Regs.4(2)(a) and 8(2)(a); Social Security Contributions and Benefits Act 1992 c.4 (SSCBA), s.171ZA). The father must also have, or expect to have, responsibility for raising the child or be in a relationship with the mother and have or expect to have main responsibility for the child's care (PALR, Regs.4(2)(b)-(c) or 8(2)(b)-(c)). Fathers who satisfy these qualifying conditions are entitled to a maximum of two consecutive weeks paternity leave to be taken in the 56 days following the birth of a child (ERA, ss.80A and 80B; PALR, Regs.4(1) and 5(1)) and may be entitled to either statutory paternity pay at this time, paid at the current rate of $£ 145.18$ per week, or $90 \%$ of normal earnings, whichever is the lesser amount (SSCBA, ss.171ZA-171ZEE; Statutory Paternity Pay and Statutory Adoption Pay (Weekly Rates) Regulations 2002/2818, Regs.2-3). Working fathers may also be entitled to shared parental leave (SPL) if both they and the mother satisfy the eligibility requirements. To qualify the working father must be an employee with at least 26 weeks' continuous employment up to and including the week before SPL is due to start (Shared Parental Leave Regulations 2014/3050 (SPLR), Regs.4, 5 and 35). In addition, the father or mother's partner must have been employed or be a self-employed earner for at least 26 out of the 66 weeks before the expected week of childbirth and have minimum earnings in the previous tax year (SPLR, Reg.36). The mother must also satisfy these conditions, or have been entitled to maternity allowance, and must have curtailed her maternity leave to utilizse SPL (Maternity and Adoption Leave (Curtailment of Statutory Rights to Leave) Regulations 2014/3052, Part 2). Working parents can share a maximum of 50 weeks in total (SPLR, Reg.6. The provision actually states that 52 weeks are available but this is subject to two weeks' compulsory maternity leave following childbirth, ERA s.72). The default position being that leave must be taken in one continuous block (SPLR, Reg.13). However, both parents can take leave concurrently and can request different non-consecutive blocks of leave for a minimum of one-week subject to employer agreement (SPLR, Part 2). 
During the extended childhood period, fathers have the right to unpaid parental leave. To qualify fathers must be 'employees', have one years' continuous service, and have responsibility for the child (Maternity and Parental Leave Etc... Regulations 1999/3312 (MPLR), Reg.13). Under the default provisions each parent is entitled to a maximum of 18 weeks' unpaid leave per child, subject to a maximum of 4 weeks per child per year (MPLR, Regs.14(1) and Reg.16 and Sch.2 para.8). Leave may be taken in weekly blocks until the child's $18^{\text {th }}$ birthday, thus enabling parents to stagger their entitlement over key stages of their child's life (Reg.16, Sch.2, para.7; as confirmed in Rodway v New Southern Railway Ltd (Formerly South Central Trains Ltd) [2005] ICR 1162; EAT decision [2005] ICR 75).

\section{The 'Absent' Fatherhood Ideology}

This ideology is characterised by paternal absence from care examined from two distinct perspectives. The first focuses on the economic provider ('breadwinner') characteristic that continues to define conceptions of masculinity and expectations of good fathering, with consequently limited recognition of caring responsibilities that impact on paid work. The second focuses on the non-resident father and how his absence from the family home can serve to limit and penalise his engagement in care.

\section{The 'absent' economic provider}

Collier and Sheldon (2008) and Collier (2010) paint a picture of such complexity regarding contemporary fatherhood, with class, race, ethnicity and geographical location intersecting to influence 'family structures and men's practices within specific locales and communities' $(2010,148)$, that it is questionable whether there is anything to be gained in capturing a normative model as a target for policy-making. This diversity suggests that any attempts by government to reinforce a dominant ideology of fatherhood are unlikely to succeed. However, Collier also acknowledges that,

'A wealth of research suggests that the experience of fatherhood continues to involve, for many if not most men, a significant temporal and spatial trade-off between the domains of work and family, and that many men, women and children continue to view the good father, at least in part, in terms of a breadwinner role' $(2010,148)$.

This stereotype has, as its exemplar, the conception of the 'standard worker' based on the notion of an unencumbered individual free to engage in full-time, permanent employment which underpins many workplace 
arrangements. This paradigm is all too recognisable to those familiar with considerations of women's experiences of paid work where it operates to exclude many mothers due to their inability to conform. In symmetry with its exclusionary effect on women's progress within workplaces, the standard worker model determines men's place within the family by reinforcing the man's role as provider and is at odds both conceptually and empirically with the demands of care-giving. This is evident in the current package of workfamily rights, which requires working fathers to establish their employment status before acknowledging their status as working father. With the sole exception of the right to time off to attend ante-natal appointments, all other work-family rights (paternity leave, SPL and unpaid parental leave) require working fathers to first be employees with an established labour market connection. The legislation thus distinguishes between mothers' and fathers' rights to spend time with their children. Whereas mothers always have the right (and responsibility) to take leave during the child's first year, fathers will only be entitled to do so if they have the requisite labour market connection, thus reinforcing the acceptability of their absence from childcare.

Furthermore, whereas women's labour market engagement has found substantial policy support, at least in terms of encouraging entry and retention, men's participation in care-giving has garnered less attention until relatively recently - initially through the provision of unpaid parental leave in 2000 (MPLR, implementing the Parental Leave Directive 96/43/EC, now repealed and replaced by Directive 2010/18/EU (PLD 2010)); followed by paternity leave in 2003 (PALR); and the right to shared childcare leave originally in 2011 as additional paternity leave (Additional Paternity Leave Regulations 2010/1055), then replaced in 2015 with SPL (SPLR). However, all of these initiatives facilitate short-time absences from work, primarily to care for very young children, and do not address the wider renegotiation of work and care responsibilities. The inevitable consequence is that it is primarily mothers who continue to have to renegotiate their relationship with paid work and care. While the right to request flexible working does arguably offer this opportunity to both parents (Flexible Working Regulations 2014/1398), there is no guarantee that the changes sought will actually be granted (see, for example, Walkingshaw v The John Martin Group, Case No: S/401126/00), or that the basis of the decisions made can be challenged (James 2006 and 2009), making it much harder for fathers to rely upon this right.

By focusing on encouraging both parents' continued participation in paid work, policy initiatives have increasingly placed emphasis on the role of men within the family without any particular attempt to incentivise this (Collier, 2001, 544). There is, thus, a failure to recognise that fathers continue to be defined by their 
breadwinning role. This is evident in the low (paternity and SPL) or unpaid (parental leave and SPL) characteristics of rights which are ostensibly directed towards working fathers. That working fathers cannot or will not take unpaid or low paid leave is well-established as a contributory factor in their lack of engagement with work-family rights (HC Women and Equality Committee, 2017), yet the current framework fails to acknowledge this by retaining current pay arrangements which disincentivise paternal engagement (HM Government, 2018). Greater recognition of the importance of the breadwinning aspect of fathers' identity through earnings-related pay for both fathers and mothers would encourage fathers to identify as worker-carers, and thus engage with care, as well as raising the status of parental care-giving for those working mothers who already do it. Such an approach would remove the necessary connection between breadwinning and paternal absence from care by acknowledging that the economic provider characteristic of male identity is not incompatible with a more active caring role.

While the current framework fails to recognise the importance of the breadwinning role, it also fails to challenge the enduring absence from care that the economic provider fatherhood ideology embodies. This is particularly evident in the lack of individual non-transferable periods of leave, so-called 'daddy days', within the current package of rights. This type of initiative may have incentivised fathers to utilise childcare leave (HM Government, 2011, 17; HM Government, 2012a, 14), not least because the benefit would be lost if it were not used (as is the case in the Nordic countries, Blum et al., 2017). The failure to include this in the SPL framework is particularly disappointing given that the benefits of such a right were highlighted by a number of stakeholders during the consultation period (TUC, 2013, paras.2-3 and 12-15; Working Families, 2013, para.2.2; and Equality and Human Rights Commission, 2013). The provision of such day-one rights for all parents with a recognised status as worker-carers would have challenged the gendering of unpaid care and paid work by addressing the derivative nature of fathers' rights. In its impact assessment of SPL, the Government estimated that, even under the most extensive revisions, only between 4-13\% of parents would use reserved periods of leave, $4-8 \%$ would use SPL and the overall periods of leave used would be relatively short compared with the leave available (HM Government, 2011, 3 and 18-20). The initial impact assessment also recognised that policies which enable the majority, or all, of the main childcare leave to be transferred to working mothers undermine gender equality with those providing reserved periods of leave better able to promote equality by acknowledging and facilitating fathers' role as caregivers (HM Government, 2011, 33). The Government justified this omission on financial grounds (HM Government, 2012a, 6), thus revealing the lack of any true political commitment to removing the support implicit in the policy framework for gendered caregiving by 
which mothers' care-related leave is seen as a necessity and fathers' as a luxury. This is reinforced in the Government's (2018) recent response to the Fathers and the Workplace Inquiry Report, in which it fails to acknowledge the benefits of non-transferable leave in favour of the current framework on the grounds that the current approach 'has the potential to be more transformative, over the longer term ... precisely because it encourages a discussion and a "maternal transfer" (p.6). This indicates the unwillingness of the Government to challenge the current ideology of paternal absence under the guise of flexibility and choice.

The ideology surrounding the father who is 'absent' due to his role as economic provider continues to permeate the current package of work-family rights so that the legislation fails to recognise the importance of the breadwinning attribute to masculine, and thus fathers', identities. While the enduring nature of the 'father as economic provider' ideology is undeniably problematic, particularly when used to justify absence from the caring role, it is also problematic to ignore it. It is only through the provision of a policy framework that recognises and values the significance of status as a paid worker for all working parents (and other carers) by enabling the renegotiation of paid work and unpaid care commitments that paternal absence from care can be challenged.

\section{The 'absent' non-resident father}

The second personification of paternal absence relates to those fathers who are physically absent from the family home because they are non-resident. Such fathers are also absent from the legal framework and related expectations of care arrangements. While in principle working fathers are able to exercise leave rights irrespective of their relationship with the child's mother, in reality many of the assumptions surrounding fathers' engagement with care are based on a heteronormative view of the family in which two different sex parents reside with their birth children who are dependent on them for care. This conceptualisation masks the diversity in family composition, overlooking arrangements beyond those that conform to a binary gendered division of work within and beyond the household. Family arrangements which fall outside of this normative model are problematised so that they are either not recognised or not supported by the provisions (Weldon-Johns, 2015). The precarious legal status of non-resident fathers was reinforced in the proposed default provisions for flexible parental leave (now SPL) which recommended that, where parents live apart, all of the transferable periods of leave and pay should be reserved for the parent with the main responsibility for care, assumed to be the resident parent (HM Government, 2012a, 22). Although the majority of respondents to the consultation were in favour of adopting this approach, some raised concerns that it failed to recognise the caring role of both parents, 
possibly undermining attempts at shared parenting (HM Government, 2012a, 22). The proposal was ultimately shelved and both parents must now qualify for and intend to use SPL (SPLR, Regs.4-5) which, whilst recognising the aim of encouraging the sharing of leave, also reinforces a dual-partnered family model.

The fact that only one individual is able to exercise fathers' rights in respect of a child means that a working father must be in a position from which he is able to negotiate his responsibilities with the child's mother. If the mother has a new partner it may be particularly difficult for a non-resident birth father to satisfy the conditions required, or to have a clear idea of his role in this context. If the mother chooses to allow her partner to exercise the rights there are no means of challenging that decision so that, even if a non-resident father intends to participate in childcare, his work-related rights will depend upon the mother's choices regarding who she shares childcare responsibilities with. The likely effects of this are evinced by research which identifies mothers' role as the gatekeepers of fathers' involvement as a consistent factor in determining the nature and extent of paternal care (Hauari and Hollingworth, 2009, 7 and 37), particularly following relationship breakdowns (Lewis, Papacosta and Warin, 2002, 4, 28-29, 31-32 and 35-37). It also reinforces the notion of the 'care-less' conception of male identity, as identified by Herring (2014) in the related family law context. In doing so, it legitimates paternal absence from care for non-resident fathers.

While it is right that those who cohabit with the child's mother, whether married or not, are legally recognised as working fathers and carers, the status of non-resident fathers requires more clarity. Law has been quick to acknowledge and regulate the financial role of such fathers (for instance, under the Child Support Act 1991 c.48, s.1), again focusing on their economic provider status. Yet their contribution to care has been neglected and often undermined, thus legitimating their absence in this respect and reinforcing its apparent connection with breadwinning. This illustrates how fathers' work-family rights are conditional on mothers' choices and inextricably linked with social perceptions of an acceptable model of fatherhood (see Collier's notion of the 'good parent', discussed above). It is disappointing that the role of the non-resident father has not been recognised more fully particularly as the most recent amendments to the package of work/family rights sit within the framework of general revisions to the sphere of family law in which there have long been calls for greater recognition of shared or co-parenting arrangements (CFA, Part 2. For a detailed discussion of the shortcomings of family law in this respect, see Herring, 2013, 43-58). In order to effectively encourage and support coparenting within all family models, family law and work-family legislation will need to be coordinated with particular attention given to fathers' caregiving rights following family separation. 
The current legal framework, consequently, continues to reinforce the 'absent' fatherhood ideology in the context of non-resident fathers. Paternal absence is again legitimised on the basis of assumptions around what fatherhood should represent, rather than recognising and responding to fathers' lived experiences and their independent rights to be fathers and caregivers. The tension between recognition as an economic provider and as an individual with caring responsibilities is also evident in this context. The recognition and valuing of relationships of care, and the desirability to maintain such relationships regardless of living arrangements, would challenge this and provide a more defined role for non-resident fathers.

\section{The 'Involved' (New) Fatherhood Ideology}

The 'involved' (new) fatherhood ideology represents the mid-point of the 'ideal' type spectrum. It is characterised by the rhetoric of 'new fatherhood' which reinforces the idea of 'involved' fathers. In reflecting Dermott's (2001) finding that what amounts to 'involved' fatherhood has been interpreted widely by working fathers, this ideology focuses specifically on the notion of 'involvement' as representing greater engagement with childcare, particularly in the post-birth period, but not necessarily greater responsibility for childcare more generally. As outlined in the first part of this article, the rhetoric of 'involved' and 'new fatherhood' has permeated much government policy with the legislation aiming to facilitate greater paternal engagement in care, yet failing to encourage equal responsibility for care.

The facilitation of fathers' greater involvement in childcare from an early stage is evident within the legal framework. The right to attend ante-natal appointments reinforces the notion of involvement by affording all working fathers with a day-one right to time off work to attend two such appointments. Indeed, this was specifically noted by the former coalition government as encouraging 'the full involvement of both parents from the earliest stages of pregnancy' as well as 'greater participation by fathers in caring for their children' (Secretary of State for Education, 2013, 22). In this context the legislation recognises the status of the father, irrespective of his connection to the workplace, and supports his involvement at this early stage. Although welcome, this provision does not fully acknowledge the father's responsibilities towards the unborn child, or indeed the mother. A failure to deal adequately with the economic implications may make it difficult for some fathers to use the right with a preferable alternative being to provide a right to a reasonable period of paid time

off to attend such appointments (Hansard, 2013). Such an approach would recognise a father's responsibility to attend by removing the need to choose between having to work for economic reasons or being directly 
involved in ante-natal care. This was suggested recently in the Fathers and the Workplace Inquiry (HC Women and Equality Committee, 2017), with the Government's disappointing response that the current approach strikes the right balance between enabling fathers to attend and placing further burdens on business (2018, p.3) underscoring a lack of commitment to facilitating greater paternal involvement.

This distinction between responsibility and involvement is even more evident in other work/family rights, which, as noted above, depend on workplace connection and employment status. In addition, payment for such rights, where it exists, is not earnings-related. Although ostensibly encouraging involved fatherhood, the operationalisation of the rights fails to recognise fathers' responsibility for care and further entrenches men's negotiable role in this context - a further example being that paternity leave can only be taken in the period overlapping maternity leave which reinforces the assumption that mothers will have primary responsibility for care-giving (James, 2006, 275; Caracciolo di Torella, 2007, 323-324; Weldon-Johns, 2011, 34). Empirical investigations of different sex couples' behaviour following the birth of a first baby note the effects of this, so that '[Men]...very quickly realise that paid work is more highly valued than the largely invisible ('feminine') work of child care at home... and they have a wider range of discourses through which to narrate and situate their choices around work and home life' (Miller 2011a, 1105). Fathers fall back into their accepted gender role following the initial period of involvement, primarily because of the gendered values associated with the roles and their 'outsider' status in relation to care, exacerbated by the lack of incentives to remain in the caring role.

Fathers' secondary role in childcare also underpins the framework of the other work/family rights. Whilst the UK's implementation of parental leave recognises that childcare responsibilities persist beyond the child's first year, that responsibility is not equally shared in practice. Gendered perceptions surrounding childcare (Bruning and Plantenga, 1999; Weldon-Johns, 2013; Caracciolo di Torella, 2014) which reflect the traditional relationship between maternity and parental leave (Blum et al., 2017, 8-11) are unchallenged with the unpaid and inflexible nature of the rights reinforcing the traditional gendering of care (McColgan, 2000, 139). This was recognised prior to the initial enactment of the legislation (Social Security Select Committee, 1998/9, paras.7-38), and remains the main justification for improving support for fathers (HC Women and Equality Committee, 2017, 30-31). The lack of any subsequent amendments to the UK's parental leave scheme, other than revisions made at EU-level in the revised PLD2010 and implemented by The Parental Leave (EU Directive) Regulations 2013/283 and the CFA, Part 7, confirms that the legislation's overriding objective is to 
promote formal equality rather than to challenge the gendering of paid work and unpaid care. The adoption of a gender-neutral rights holder approach, which entitles all parents to equal treatment, does not recognise the particular needs of working fathers as rights holders in this respect by accepting (House of Lords Hansard, 1998, Col.884, per Baroness Blatch at Cols.905-906; SSSC, 1998/9, para.10; Department of Trade and Industry, 2001, 8), or failing to challenge, the perception that working mothers are the primary caregivers (Finch, 2006, 138, see also Larsen, Taylor-Gooby and Kananen, 2004).

The right to SPL has also failed to substantially challenge the persisting gendered approach to care that has characterised the UK's package of work/family rights. At worst this reinforces paternal absence from care, at best it enables some fathers to be more involved, while continuing to legitimise their lack of responsibility for care evident in their 'dependent' status within SPL (Aitkinson (2017) and Mitchell (2015)). Fathers' ability to utilise this right depends on their employment status and connection as well as on those of the working mother and her choices regarding leave. Empirical work has shown that such factors can have a make or break impact on working fathers' involvement in caring for their pre-school children which is largely shaped by the maternal relationship with paid work as mothers' working hours continue to be the main predictor of fathers' engagement with childcare (Norman, Elliott and Fagan, 2014). This is reflected in the way in which the legislation operates in practice, particularly in the distinctions between entitlements to enhanced pay in the child's first year (Aitkinson, 2017). The issue here stems from government guidance, which notes that shared parental leave pay (SPLP) need not be paid at the same rate as enhanced maternity pay (Department for Business Innovation and Skills, 2014, para.77), thus drawing a clear distinction between the value of maternity leave and gender-neutral SPL, which encourages employers to disincentivise paternal care. This is evident in the narrow case law in which it has been argued that the failure to provide enhanced SPLP discriminates against working fathers. The case law has approached this from both a direct and indirect discrimination perspective, with the direct discrimination claims being unsuccessful thus far (Shuter v Ford Motor Co. Ltd [2014] EqLR 717; Hextall v Chief Constable of Leicestershire Police (ET) ET/2601223/2015; Ali v Capita Customer Management Ltd UKEAT/0161/17/BA) because the pregnancy and maternity exception in s.18 EqA prevents fathers from comparing themselves with working mothers on maternity leave (Shuter). While it is obviously important to protect pregnant workers and those using maternity leave from discrimination, this approach further entrenches the gendering of caring roles by failing to acknowledge that working fathers are in a similar position to working mothers with regards to their caring responsibilities, particularly following the compulsory maternity leave period. The ET in Shuter reinforced this approach by rejecting the argument that the purpose of additional 
paternity leave (now SPL) was to 'detach' maternity leave from the protection of the mother's health and safety to focus on caring for the child. In contrast, the ET in Ali (ET/1800990/2016) accepted this argument and agreed that a distinction could be drawn between compulsory maternity leave and childcare leave thereafter so that the failure to extend enhanced payments to fathers during the childcare leave period amounted to direct sex discrimination. In reaching this decision, the ET adopted the line of reasoning evident in the decisions of the CJEU, recognising the role of working fathers and the de-gendering of care. However, this decision was overturned on appeal (UKEAT/0161/17/BA), following the approach in Shuter and by the ET in Hextall. This represents a backwards step in the recognition of fathers as worker-carers.

The question of whether failing to extend enhanced benefits to SPL amounts to indirect sex discrimination remains open. In Snell v Network Rail Infrastructure Ltd 2016 WL 05484817 the decision was clearer since the employer accepted that providing enhanced SPLP only to working mothers was indirectly discriminatory. More recently, the EAT in Hextall held that paying the statutory rate for SPLP could amount to indirect sex discrimination against men since women had the option to take maternity leave with enhanced pay and men did not (UKEAT/0139/17/DA). In its decision the EAT held that the ET had erred in holding that women on maternity leave could not be included in the pool of comparators for indirect discrimination just because they were excluded as comparators for direct discrimination (para.62). The key argument regarding the potential disadvantage suffered by fathers here is the same as that noted above in relation to unpaid leave. It requires fathers to make the choice between fully paid work or low paid childcare leave, with the likely choice being paid work. Mothers do not need to make such a choice as they are able to utilise maternity leave with enhanced payments. Of course indirect sex discrimination can be justified making it more difficult for fathers to succeed and to receive recognition as working carers on the same grounds as working mothers.

The case law to date illustrates the unwillingness of UK courts to acknowledge the distinction between the act of childbirth and the gender-neutral performance of care (Fredman, 2014). The differences in mothers' and fathers' rights' regimes include steeper employment conditions imposed on fathers which reinforce the traditional gendered roles of female carer/male breadwinner and perpetuate men's self-identification as workers rather than carers or worker-carers, (Collier, 2001, 544). The current frameworks assume that fathers will adopt a secondary role either by limiting periods of family-related leave and when it can be taken, or by reinforcing that their role is negligible and/or negotiable as compared with the enforced role of the mother. The operation 
of the rights in practice highlights the gap between the rhetoric of 'new fatherhood' and the reality of fathers' lived experiences of care.

While the tentative shift towards self-standing rights for working fathers has provided a long overdue challenge to the gendering of care, the current package of rights falls woefully short. The incorporation of the state's vision of what men's familial role should be reflects the ideological pursuit of formal gender equality rather than any attempt to address the needs or aspirations of working fathers (Collier, 1999, 177-178). Thus, while fathers are expected to be involved in care, the means by which that can be translated into responsibility for care and recognition of the importance of economic factors in care-related decision making is absent. The legal framework thus continues to reflect two conflicting conceptualisations of fatherhood, 'absent' or 'involved', with neither 'responsible'. The aspirational paradigm of 'new fatherhood' has not been matched by any attempt to incorporate the needs of working fathers which perpetuates a lack of control over their ability to engage with care-giving and reaffirms its low status and value. This retrenchment of strong cultural and institutional norms mean that policy ideals have little impact, so that ' $[\mathrm{T}]$ he legacy of patriarchal and structural arrangements, men's power and 'choices' cannot be erased from contemporary debates or experiences even if there is a desire to do so’' (Miller 2011a, 1105).

\section{The 'Active' Fatherhood Ideology}

The 'active' fatherhood ideology represents the other end of the 'ideal' type spectrum. It reflects the aspirations and rhetoric of 'new fatherhood' and is characterised by fathers being able to undertake a more equal responsibility for care. As has already been shown, while UK legislation has aimed to facilitate this, it has not in practice enabled working fathers to adopt equal responsibility for care. This is in contrast with developments at EU-level with some recognition of fathers as worker-carers emerging in the jurisprudence of the CJEU in $C$ 104/09 Roca Alvarezv Sesa Start Espana ETT SA [2011] 1 CMLR 28 and Case C-222/14 Maistrellis v Ypourgos Dikaiosynis, Diafaneias kai Anthropinon Dikaiomaton EU:C:2015:473. In both cases the CJEU acknowledged that the position of working fathers, in trying to combine work and care responsibilities, is the same as that of working mothers (Roca Alvarez, para.24 and Maistrellis, para.47). This is indicative of a move towards the degendering of caring responsibilities which is necessary for fathers' recognition as earner-carers (see further Caracciolo di Torella, 2014 and Fredman, 2014). Such a shift reflects the active fatherhood ideology which 
recognises that the gender of the caregiver is irrelevant as it is the presence of a qualifying relationship of care that is important.

This approach appears to be endorsed at the EU level by the proposed Work-life Balance Directive COM/2017/0253 final, which would repeal and replace the PLD 2010. While not introducing any new rights specifically for working fathers in the UK context (parental leave (art.5); paternity leave (art.4)), the proposal signifies a commitment to existing protections and the creation of a new floor of work-family rights which clearly recognises fathers as worker-carers and thus has the potential to coordinate and reconceptualise the work-family framework (Caracciolo di Torella, 2017). Notwithstanding the limitations of the proposed Directive, its potential for the future development of fathers' rights and recognition of different relationships of care (see, for example, the right to carers' leave (art.6)) offer great promise for the legal recognition of active fatherhood at the EU-level. The same cannot be said for of the UK posing particular concerns for working fathers post-Brexit. The domestic work-family framework is currently in a state of stagnation, particularly in relation to working fathers, leaving related rights vulnerable to further entrenchment of the absent fatherhood classification post-Brexit with little hope for recognition of the broader spectrum of fatherhood ideologies that working fathers may identify with.

\section{Conclusions}

By exploring the nature and extent of fathers' rights in the UK we have shown how gendered assumptions and perceptions are reproduced in the work-family law and policy framework. This analysis has identified policymakers' reliance on two conflicting and equally unhelpful ideologies pertaining to fatherhood whose coexistence actually serves to constrain working fathers' involvement in the provision of childcare. The unrealistic notion of new fatherhood by which fathers are required to conform to a more care-centric profile is seriously at odds with pre-existing notions of father as breadwinner and mother as carer by which fathers are more likely to self-identify as workers rather than carers or worker-carers. The derivative nature of men's workfamily rights which are highly dependent on those available to mothers has the unfortunate effect of further entrenching men's identities as providers of income rather than of care, as evident in the absent fatherhood ideology. The UK's law and policy framework reinforces this polarisation in that it seeks, on the one hand, to reorient men's engagement through notions of shared care but does little to incentivise or enable men and women to actually participate in this ideal whilst, on the other hand, providing reduced or restricted rights to fathers in comparison to those available to mothers, as evident in the involved fatherhood ideology. 
Recent attempts to extend fathers' rights have added further complexity to an already confusing web of provision. In the wider context, an effective review would have to consider not only work-family policy, but also tax, welfare and family law provisions with a view to instilling some cohesion across these currently disparate areas (Busby, 2013). The success of any policy initiative will depend on a clear commitment to the achievement of a more equal sharing of paid work and unpaid care between men and women which, in the current neoliberal landscape with its focus on austerity, seems unlikely. Government policy which prioritises participation in paid work regardless of the quality of that work can only serve to further entrench the gendering of unpaid care and labour market participation between different sex couples, which is at odds with the apparent aim of improving working fathers' ability to provide care. Even within the relatively narrow field of workfamily law and policy, mixed messages abound which give rise to a gaping implementation gap in relation to how families organise paid work and unpaid care, how they would like to do so and how relevant provisions do and should facilitate and support this. This does little either to assist in the re-conceptualisation of fathers as involved carers/worker-carers, necessary to make the active fatherhood ideology a reality. Nor does it challenge the dominant ideology of mothers as the primary providers of care which underpins the work-family framework, casting fatherhood into the shadows. McGlynn has identified the need to revisit law's assumptions about motherhood and, in doing so, to 'recast the ideological preconceptions on which the existing law is founded' $(2000,44)$. While that message still holds true in the UK, with a continuing need for law and policy which is capable of facilitating flexibility in family life rather than attempting to mould it in certain likenesses, it is apparently beginning to be challenged in the EU which could result in regression in this context in a post-Brexit UK.

As long as a pernicious and gender-bound ideology surrounding motherhood sustains, fathers' rights will continue to be viewed as secondary to and derivative from those of mothers. Rejecting the quest for a unitary notion of 'fatherhood' for the purpose of framing policy, Collier has argued against 'an essentialist conceptualisation of the 'masculinity of law', an idea that has served to erase much of the complexity and heterogeneity of the personal lives of women and men' $(2010,128)$. If gender stereotyping is to be overcome in the context of work-family law and policy, what is required is a flexible, responsive policy framework capable of capturing the wide range of practices and attachments to care-giving that exist regardless of the personal characteristics of the caregiver (Busby, 2011). In this respect, it is perhaps worth considering the father-child relationship in more depth. In the specific context of fathering, Dermott's empirical observations about intimacy 
are particularly helpful in drawing a distinction between 'spending time' and 'making time' $(2008,142)$. Dermott's assertion that contemporary fatherhood should be conceptualised as an intimate relationship 'centred on a personal connection at the expense of participation in the work of childcare' - leads her to conclude that 'the practicalities of 'intimate fatherhood' are fluid and open to negotiation' $(2008,1)$. This is surely an ideal starting point: a non-prescriptive and flexible approach aimed at facilitating such intimate relationships would appear to be a very sound basis on which to build a work-family law and policy framework for all providers of care regardless of gender or biological relationship.

\section{References}

Abbott, P., Nativel, C., and Wallace, C., 2013. Dual Earner Parents Strategies for Reconciling Work and Care in Seven European Countries. Observatoire de la Société Britannique. 14, 73-97, available: http://osb.revues.org/1521?lang=en.

Atkinson, J.L., 2017. Shared Parental Leave in the UK: can it advance gender equality by changing fathers into co-parents? International Journal of Law in Context. 13(3), 356-368.

Blum, S., Koslowski, A., and Moss, P, 2017. International Review of Leave Policies and Related Research 2017. International Network on Leave Policies and Research.

Bruning, G., and Plantenga, J., 1999. Parental Leave and Equal Opportunities: Experiences in Eight European Countries. Journal of European Social Policy, 9(3), 195-209.

Busby, N., 2011. A Right to Care: Unpaid Care Work in European Employment Law. Oxford: Oxford University Press.

Busby, N., 2013. Labour law, Family Law and Care: A Plea for Convergence. In: J. Herring and J. Wallbank (Eds). Vulnerabilities, Care and Family Law. Oxon: Routledge.

Busby, N., 2014. Unpaid Care, Paid Work and Austerity: A Research Note. feminists@law, 4(1).

Busby, N., 2018. Brexit, Gender Equality and Scotland: In and Out of the Shadowlands' in M. Dustin, N. Ferreira and S. Milns (Eds). Brexit: Gender and Queer Perspectives, Palgrave Macmillan (forthcoming).

Caracciolo Di Torella, E., 2007. New Labour, New Dads — The Impact of Family Friendly Legislation on Fathers. Industrial Law Journal, 36(3), 318-328.

Caracciolo di Torella, E., 2014. Brave New Fathers for a Brave New World? Fathers as Caregivers in an Evolving European Union. European Law Journal, 20(1), 88-106.

Caracciolo di Torella, E., 2017. An emerging right to care in the EU: a "New Start to Support Work-Life Balance for Parents and Carers". ERA Forum, 18, 187-198. 
Clarke, J., and Newman, J., 2012. The alchemy of austerity. Critical Social Policy, 32(3), 299-319.

Collier, R., 1999. Feminising' the Workplace? Law, the 'Good Parent' and the 'Problem of Men. In: A. Morris and T. O'Donnell (Eds), Feminist Perspectives on Employment Law. London: Cavendish Publishing Limited. Collier, R., 2001. A Hard Time to Be a Father?: Reassessing the Relationship Between Law, Policy, and Family (Practices). Journal of Law and Society, 28(4), 520-545.

Collier, R., 2010. Men, Law and Gender: Essays on the 'man' of law. Oxon: Routledge.

Collier, R., and Sheldon, S., 2008. Fragmenting Fatherhood: A Socio-Legal Study. Oxford: Hart Publishing. Conley, H., 2012. Economic crisis, austerity and gender equality - the UK case. European Gender Equality Law Review, 2, 14-19

Connolly, S., Aldrich, M., O’Brien, M., Speight, S., and Poole, E., 2013. Fathers and Work', Fathers, Work and Families in the $21^{\text {st }}$ Century. Briefing paper June, available: http://www.modernfatherhood.org/publications/fathers-and-work/

Crompton, R., 1999. Restructuring Gender Relations and Employment: The Decline of the Male Breadwinner. Oxford: Oxford University Press.

Crompton, R., and Lyonette, C., 2008. Who does the housework? The division of labour within the home. In: A. Park, J. Curtice, K. Thomson, M. Phillips, M. Johnson, and E. Cleary (Eds), British Social Attitudes. London: Sage.

Dex, S., Hawkes, D., Joshi, H., and Ward, K., 2005. Parents' employment and childcare. In: S. Dex and H. Joshi (Eds), Children of the 21st century: From birth to nine months. Bristol: Policy Press.

Dermott, E., 2001. New Fatherhood in Practice? - Parental Leave in the UK. The International Journal of Sociology and Social Policy, 21(4-6), 145-164.

Dermott, E., 2005. Time and Labour: Fathers' Perceptions of Employment and Childcare. Sociological Review, $53,89-103$.

Dermott, E., 2008. Intimate Fatherhood: A Sociological Analysis. London: Routledge.

Department of Trade and Industry, 2001. Parental Leave Consultation. London: Department of Trade and Industry.

Department for Business Innovation and Skills, 2014. Employers' Technical Guide to Shared Parental Leave and Pay, London: Department for Business, Innovation and Skills.

Equality and Human Rights Commission, 2009. Working Better: fathers, family and work contemporary perspectives. Research summary 41. London: Equality and Human Rights Commission. 
Equality and Human Rights Commission, 2013. Memorandum submitted by Equality and Human Rights Commission on the Children and Families Bill. CF 66.

Equality and Human Rights Commission, 2017. Measuring Up, Report 7: Public Authorities' performance in meeting the Scottish Specific Equality Duties. Available:

https://www.equalityhumanrights.com/sites/default/files/m_u_7_formatted_final.pdf

Equal Opportunities Commission, 2006. Gender Equality Duty Code of Practice for England and Wales. London: EOC.

Finch, N., 2006. Childcare and Parental Leave. In: J. Bradshaw and A. Hatland (Eds), Social Policy, Employment and Family Change in Comparative Perspective. Cheltenham: Edward Elgar Publishing.

Fredman, S., 2014. Reversing roles: Bringing men into the frame. International Journal of Law in Context, 10(4), 442-459.

Fudge, J., and Owens, R., (Eds), 2006. Precarious Work, Women and the New Economy: The Challenge to Legal Norms. Oxford: Hart Publishing.

Gershuny, J., 2000. Changing Times: Work and Leisure in Post-industrial Society. Oxford: Oxford University Press.

Gregory, A. and Milner, S., 2011. What is "New" about Fatherhood? The Social Construction of Fatherhood in France and the UK. Men and Masculinities,14(5), 588-606.

Hansard, 2013. Children and Families Bill. Committee Debate: $4^{\text {th }}$ sitting: House of Commons, 7 March 2013. Hauari, H., and Hollingworth, K., 2009. Understanding Fathering, Masculinity, diversity and change. York: Joseph Rowntree Foundation.

Hearn, J., 2004. From Hegemonic Masculinity to the Hegemony of Men. Feminist Theory, 5(1), 149-72.

Hepple, B., 2011. Enforcing Equality Law: Two Steps Forward and Two Steps Backwards for Reflexive Regulation. Industrial Law Journal, 40 (4), 315-335.

Herring, J., 2014. Making Family Law More Careful. In: Wallbank and J. Herring, (Eds). Vulnerabilities, Care and Family Law. Oxon: Routledge.

HC Women and Equality Committee, (2017). Fathers and the Workplace: First Report of Session 2017-19. HC 358.

HM Government, 2011. Consultation on Modern Workplaces, Flexible Parental Leave: Impact Assessment. HM Government, 2012a. Modern workplaces - government response on flexible parental leave.

HM Government, 2012b. Modern workplaces - government response on flexible working. 
HM Government, 2018. Fathers and the Workplace: Government's response to the Committee's First Report of Session 2017-19. HC 1076.

House of Lords Hansard, 1998. Work and the Family. (13 October 1998), Col.884.

James, G., 2006. The Work and Families Act 2006: Legislation to improve choice and flexibility? Industrial Law Journal, 35(3), 272-278.

James, G., 2009. Mothers and Fathers as Parents and Workers; Family Friendly Employment Policies in an Era of Shifting Identities. Journal of Social Welfare and Family Law, 31(3), 271-283.

Larsen, T.P., Taylor-Gooby, P., and Kananen, J., 2004. The myth of a dual-earner society. New policy discourses in European welfare states. WRAMSOC Project Berlin Conference.

Lewis, C., 2000. A Man's Place in the Home: Fathers and Families in the UK. York: Joseph Rowntree Foundation.

Lewis, C., Papacosta, A., and Warin, J., 2002. Cohabitation, Separation and Fatherhood. York: Joseph Rowntree Foundation.

MacLeavy, J., 2011. A 'new politics' of austerity, workfare and gender? The UK coalition government's welfare reform proposals. Cambridge Journal of Regions, Economy and Society, 4(3), 355-367.

McColgan, A., 2000. Family Friendly Frolics? The Maternity and Parental Leave etc. Regulations 1999. Industrial Law Journal 29(2), 125-144.

McGlynn, C., 2000. Ideologies of Motherhood in European Community Sex Equality Law. European Law Journal, 6(1), 29-44.

Miller, T., 2011a. Falling back into Gender? Men's Narratives and Practices around First-time Fatherhood. Sociology, 45(6) 1094-1109.

Miller, T., 2011b. Making Sense of Fatherhood: Gender, Caring and Work. Cambridge, Cambridge University Press.

Mitchell, G., 2015. Encouraging fathers to care: The Children and Families Act 2014 and shared parental leave. Industrial Law Journal, 44(1), 123-133.

Norman, H., Elliott, M., and Fagan, C., 2014. Which fathers are the most involved in taking care of their toddlers in the UK? An investigation of the predictors of paternal involvement. Community, Work and Family, 17(2), $163-180$.

Park, P., Curtice, R., Thomson, K., Phillips, M., and Johnson, M., 2007. British Social Attitudes, the 23rd Report: perspectives on a changing society. London, National Centre for Social Research.

Pateman, C., 1988. The Sexual Contract. London: Polity Press. 
O’Brien, M., 2005. Shared Caring: Bringing Fathers into the Frame. Working Paper Series No. 18, Manchester: Equal Opportunities Commission.

O’Brien, M., and Shemilt, I., 2003. Working fathers: earning and caring. Manchester: EOC.

Scourfield, J., and Drakeford, M., 2002. New Labour and the 'Problem of Men'. Critical Social Policy, 22(4), 619-640.

Secretary of State for Education, 2013. Children and Families Bill 2013: Contextual Information and Responses to Pre-Legislative Scrutiny. Cmd $8540 . \quad$ Available: http://www.officialdocuments.gov.uk/document/cm85/8540/8540.pdf.

Smart, C., 1997. Wishful thinking and harmful; tinkering? Sociological reflections on family policy. Journal of Social Policy, 26(3), 301-321.

Smart, C., and Neale, B., 1999. “I Hadn’t Really Thought About It”: New Identities/New Fatherhoods. In: J. Seymour and P. Bagguley, (Eds). Relating Intimacies: Power and Resistance. New York: St Martin's Press. Social Security Select Committee, 1998/9. Social Security Implications of Parental Leave. HC 543 (ISBN 0 $105564311)$.

TUC, 2013. Memorandum submitted by TUC on the Children and Families Bill. CF 80.

Wallbank, J., and Herring, J., (Eds), 2014. Vulnerabilities, Care and Family Law. Oxon: Routledge.

Weldon-Johns, M., 2011, The Additional Paternity Leave Regulations 2010: a new dawn or more 'sound-bite' legislation? Journal of Social Welfare \& Family Law, 33(1), 25-38.

Weldon-Johns, M., 2013. EU Work-Family Policies-Challenging Parental Roles or Reinforcing Gendered Stereotypes? European Law Journal, 19(2), 1-20.

Weldon-Johns, M., 2015. From modern workplaces to modern families - Re-envisioning the work-family concept. Journal of Social Welfare and Family Law, 37(4), 395-415.

Working Families, 2011. Working and Fathers: Combining Work and Family Life. London: Working Families. Working Families, 2013. Memorandum submitted by Working Families on the Children and Families Bill. CF 64.

\section{Word count: 11854}

